\title{
Action Research: A Methodology for Organizational Change ${ }^{1}$
}

\author{
Dale Pracht, Andrew Toelle, and Brent Broaddus²
}

Change is inevitable. When working within an organization, figuring out what needs to change can be a big issue. Having quality information available for use can make the decision process clearer and more effective. Action research is a methodology that can be used by people internal to an organization to identify what changes need to be made.

\section{What is action research?}

Action research was first developed by Kurt Lewin, "a social scientist who devised the 'field theory' of concepts known as typographical psychology" (Adelman, 1993). Action research is a qualitative approach that "is done by or with insiders to an organization or community, but never to or on them. It is a reflective process but is different from isolated spontaneous reflection in that it is deliberately and systematically undertaken and generally requires that some form of evidence be presented to support assertions" (Herr \& Anderson, 2005, p. 3). Finally, the result of an action research process is the implementation of new processes.

In 1991, Elliot suggested that action research is a cyclical process that requires repeated evaluation and change. This process in ongoing with changes taking place over time. Action research is a methodology for intentionally and deliberately devising first, what needs to change, and second, how to go about change. Action research has been graphically illustrated by Elliot (1991) and can be seen in Figure 1.

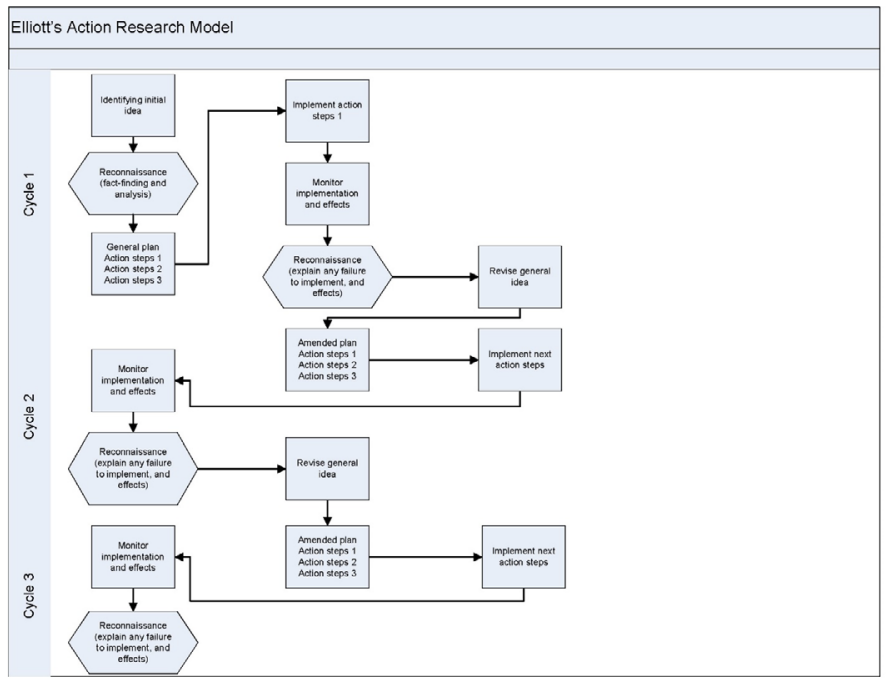

Figure 1. Elliott's action research model.

\section{The Action Research Cycle}

Identify the idea. This step will determine the focus of your research and give you time to figure out the key individuals who can assist in making the process work. This is where the researcher identifies what the situation is that will be resolved through the action research process.

1. This document is $4 \mathrm{H} 424$, one of a series of the Florida 4-H Youth Development Program, UF/IFAS Extension. Original publication date February 2022. Visit the EDIS website at https://edis.ifas.ufl.edu for the currently supported version of this publication.

2. Dale Pracht, associate professor, Department of Family, Youth and Community Sciences; Andrew Toelle, Extension agent IV, 4-H regional specialized agent, Northeast District; and Brent Broaddus, Extension agent III, 4-H regional specialized agent, Southwest District; UF/IFAS Extension, Gainesville, FL 32611.

The Institute of Food and Agricultural Sciences (IFAS) is an Equal Opportunity Institution authorized to provide research, educational information and other services

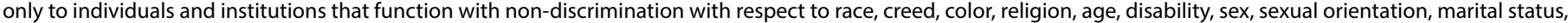

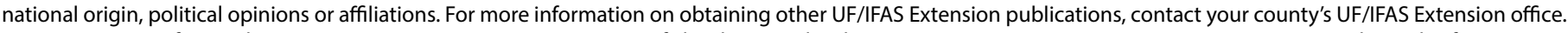
U.S. Department of Agriculture, UF/IFAS Extension Service, University of Florida, IFAS, Florida A \& M University Cooperative Extension Program, and Boards of County Commissioners Cooperating. Andra Johnson, dean for UF/IFAS Extension. 
Reconnaissance. There are two parts to this step, factfinding and analysis. In this step, the researcher gathers information about the idea targeted in step one. This can be done through interviews, observations, looking over other "artifacts" (newsletters, user manuals, etc.) to gather data for analysis. Once gathered, the data is analyzed for details of the "idea" and to develop informed suggestions on how to tackle the problem.

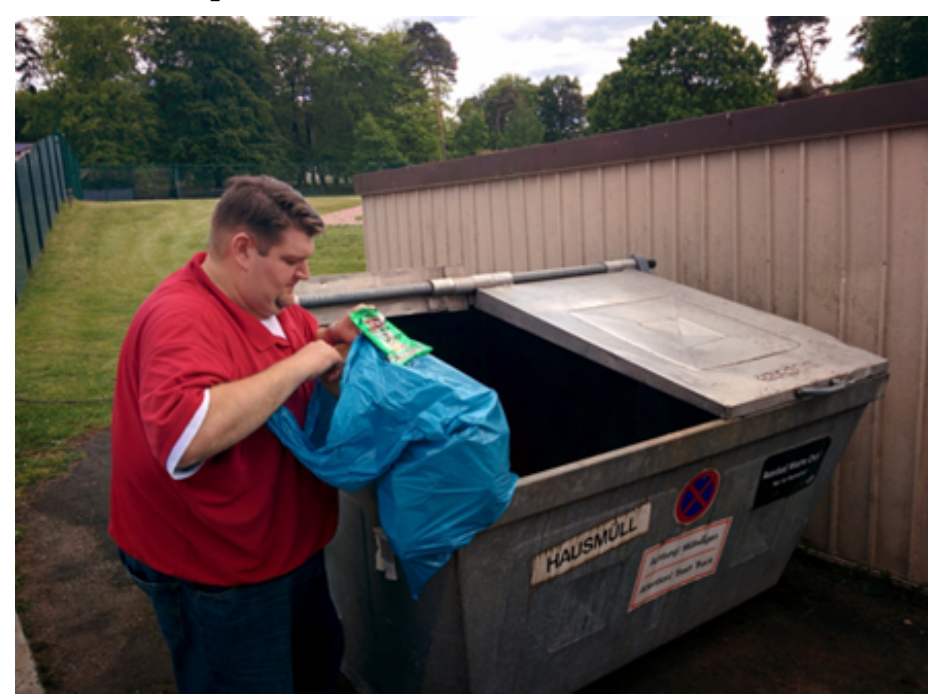

Figure 2. Data collection comes in many forms. Credits: Andrew Toelle, UF/IFAS

General plan. This step is where the researcher develops the implementation plan for the following action steps. Each action step should be taken separately. This plan should include what is going to change, who is going to do the changing, any negotiations that may be needed to make the change (such as with a supervisor), and any resources needed to make the change. When forming the plan, be aware of data control and privacy.

Implement action steps. This is the step where the people within the system make change.

Monitor. Action research is cyclical and requires monitoring. This allows the plan to be modified to better fit the on-the-ground realities. The cycle repeats with further reconnaissance and redefining the idea until the change is effective.

Sagor (2000) has developed another model for action research. There are seven steps in this model of participatory action research. They are selecting a focus, clarifying theories, identifying research question, collecting data, analyzing data, reporting results, and taking informed action (Sagor, 2000).

Select a focus. This step is where you determine what you are going to focus on. It should be fairly specific, but not so defined that you close off other avenues as they present themselves. For example, if you feel like your Extension volunteer program is not retaining volunteers past the initial training stage, you may decide to make your focus volunteer retention.

Clarify theories. Are there scientific theories that could explain the behavior you wish to examine in your focus? There are usually several that could be used, but at this stage you would identify the one that you think best describes what it is you are trying to discover. In our example, you would choose a theory from the volunteerism/human sciences realm.

Identify the research question. This step has you identify specifically what you will study. This question will be much more specific than the initial step-for example, "What can be done to increase volunteer retention participation past the training stage?"

Collect data. Data for action research can come from many different sources. As in our example, you may wish to conduct a post-volunteer exit interview or a current volunteer focus group to gain insight into what is going on. Other sources can be used, such as annual reports.

Analyze data. Take a look at the data using the lens of the theory chosen. Do themes appear? Do the data sources triangulate well with each other? You may conduct a thematic analysis of the focus group and exit interviews and triangulate these themes with other artifacts to assure that you have quality data. At this point, it is also important to note that action research allows for and expects the persons who are being "researched" will be a part of this entire process.

Report results. Many times research is published in journals but never shared with those who were subjects in the research. Action research requires that the findings be shared far and wide, with an eye toward doing something or taking action. In our example, the findings would be shared with the people within the organization. This can be done through presentation, tweets, or anyway the organization prefers to receive information. When the information is being shared, the actions that will be taken as a result of this effort should be included.

Take informed action. Finally, taking action! After this time of inquiry and determination, action is required. However, this action is informed and supported by the data of the study. In our example, perhaps it was discovered that many volunteers were leaving after training because all they 
really wanted was the information. With this information in hand, a new screening process could be implemented and other classes offered for those only wanting information verses those wishing to give back. Finally, is what you are doing working? To answer this question, the process begins again.

In summary, participatory action research is a good method for agencies to identify issues and take informed action to correct them. It is a deliberate process which allows for input from many different sources. By using this process, more informed decisions about change can be made and implemented.

\section{References}

Adelman, C. (1993). Kurt Lewin and the origins of action research. Educational Action Research, 1(1), 7-24. https:// doi.org/10.1080/0965079930010102

Elliot, J. (1991). Action research for educational change. Open University Press.

Herr, K., \& Anderson, G. L. (Eds.). (2005). The action research dissertation: A guide for students and faculty. Sage.

Stringer, E. T. (2008). Action research in education (2nd ed.). New Jersey: Pearson. 